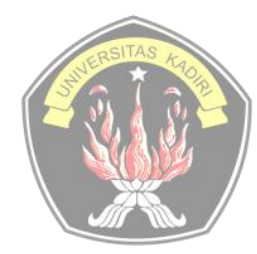

Tersedia online di

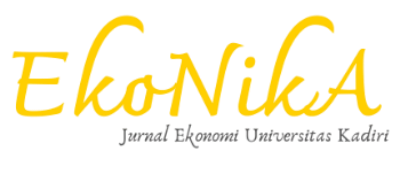

\title{
Pengembangan Sumber Daya Manusia Berbasis Kompetensi Sebagai Upaya Meningkatkan Kinerja Organisasi Di Pt.Pertamina Lubricant
}

\section{Jakarta}

\author{
Ilma Gozali ${ }^{1}$, Sri Iswati ${ }^{2}$, Subagyo Adam ${ }^{3}$ \\ ${ }^{1,2,3}$ Universitas Airlangga, Surabaya, Indonesia \\ email: ${ }^{1}$ ilma.gozali@gmail.com, ${ }^{2}$ iswati@feb.unair.ac.id, ${ }^{3}$ subagyo.adam@fisip.unair
}

Artikel History:

Artikel masuk : 01-07-2020

Artikel revisi : 16-08-2020

Artikel diterima : 21-09-2020

Keywords:

Organizational Performance;

Human Resource Development;

Competence

\begin{abstract}
ABSTRAK
Peranan manusia dalam organisasi sangat penting. tuntutan teknologi dan persaingan dunia usaha,maka kompetensi sumber daya manusia dalam organisasi harus dapat dioptimalkan melalui pelatihan dan pengembangan karyawan yang berbasis kompetensi. Hal ini memberikan dampak yang positif ketika SDM yang kompeten mampu membawa keberhasilan pribadinya pada peningkatan kinerja organisasi. Pengembangan manusia dalam organisasi memberikan kualitas dan kemampuan kerja yang akan berdampak pada peningkatan kinerja organisasi. PT. Pertamina Lubricant dalam rangka menyongsong Word Class Company 2020 mempersiapkan segala sesuatunya khususnya kesiapan Sumber Daya Manusia guna mancapai hal tersebut. Saat ini training Sumber daya manusia untuk meningkatkan kompetensi baik secara internal maupun eksternal dalam lingkup nasional maupun internasional sudah mulai dilaksanakan. Disamping itu sertifikasi kompetensi bagi para personil PT.Pertamina Lubricant oleh Lembaga yang berkompeten untuk untuk pekerjaan-pekejaan tertentu guna mendapatkan pengakuan baik secara nasional maupun internasinal juga diikuti. Intinya penelitian ini bertujuan untuk meningkatkan kompetensi profesi Tenaga kerja dan atau mempertahankan kompetensi profesi Tenaga kerja untuk meningkatkan kinerja dalam suatu perusahaan yang sedang mengalami perubahan teknologi produksi dari yang bersifat manual ke modern dengan Tenaga kerja yang sama, yang pelatihannya dilaksanakan secara internal, integrated dan coordinative. Kondisi ini semua masih dalam proses namun tanda-tanda kearah perbaikan dirasakan semakin tampak. Proses inilah yang menjadi kajian kita saat ini.
\end{abstract}


The role of humans in organizations is very important. the demands of technology and competition in the business world, therefore the competence of human resources in the organization must be optimized through competency-based training and employee development. This has a positive impact when competent human resources are able to bring personal success to improve organizational performance. Human development in the organization provides quality and work ability that will have an impact on improving organizational performance. PT. Pertamina Lubricant in welcoming the Word Class Company - 2020 prepares everything, especially the readiness of Human Resources to achieve this. Currently, training on human resources to improve competence both internally and externally in the national and international scope has begun. In addition, competency certification for PT.Pertamina Lubricant personnel by competent institutions for certain jobs in order to get recognition both nationally and internationally is also followed. In essence, this study aims to improve the professional competence of the workforce and / or maintain the professional competence of the workforce to improve performance in a company that is undergoing a change in production technology from manual to modern with the same workforce, whose training is carried out internally, integrated and coordinatively. . These conditions are all still in process, but signs of improvement are being felt. This process is our current study.

\section{PENDAHULUAN}

Keberadaan sumber daya manusia dalam suatu organisasi merupakan aset yang berharga bagi organisasi itu sendiri. Keberhasilan suatu organisasi ditentukan dari kualitas orang-orang yang berada di dalamnya. SDM akan bekerja secara optimal jika organisasi dapat mendukung kemajuan karir mereka dengan melihat apa sebenarnya kompetensi mereka. Biasanya,pengembangan SDM berbasis kompetensi akan mempertinggi produktivitas karyawan sehingga kualitas kerja pun lebih tinggi pula dan berujung pada puasnya pelanggan dan organisasi akan diuntungkan. PT.Pertamina Lubricant sebagai anak perusahaan PT.Pertamina (Persero) saat ini sedang membangun kompetensi Sumberdaya Manusia. Berbagai cara dilakukan mulai dari mensertifikasi Kompetensi tenaga kerja intinya melalui Lembaga Sertifikasi Kompetensi Personil baik Nasional maupun Internasional tergantung kebutuhannya. Juga melakukan Training dan Workshop secara internal maupuneksternal. Agar penerapan model-model kompetensi di dalam organisasi dapat memberikan nilai kompetitif, dalam proses pengembangannya harus direncanakan dengan baik dan harus selaras dengan Pengembangan Sumber Daya ..... 
misi, strategi, tantangan maupun sasaran yang ingin dicapai oleh organisasi. Selain itu demi menjaga agar penerapan model-model kompetensi dapat berjalan secara efektif ,sebaiknya dipilih aplikasi model kompetensi yang akan memenuhi kebutuhan mendasar organisasi, mudah dilaksankan, dan dapat menunjukan hasil yang cepat.Praktik-praktik ini sangat penting jika para pemilik perusahaan ingin menguak bakat yang sesungguhnya yang dimilikioleh para karyawan. .Tipe praktik yang menjadi focus perhatian disini adalah :

a) Mengidentifkasi keterampilan yang tepat yang dibutuhkan untuk meraih sukses dilingkungan dewasa ini .

b) Menyeleksi pengunjuk kerja terbaik dan karyawan dengan potensi yang sangat besar.

c) Merencanakan untuk memenuhi kebutuhan individual dan organisasi.

d) Menilai kinerja dan pemerolehan keterampilan.

e) Membayar untuk keterampilan.

f) Membangun lingkungan kerja yang terbaik dan unjuk kerja kolektif

g) Mengelola motivasi untuk peningkatan kinerja.

\section{TINJAUAN PUSTAKA}

\section{PENGEMBANGAN SUMBER DAYA MANUSIA BERBASIS KOMPETENSI P}

engembangan SDM berbasis kompetensi dilakukan agar dapat memberikan hasil sesuai dengan tujuan dan sasaran organisasi dengan standar kinerja yang telah ditetapkan. Kompetensi yang dimiliki seorang karyawan secara individual harus dapat mendukung pelaksanaan visi misi organisasi melalui kinerja strategis organisasi tersebut. Oleh karena itu kinerja individu dalam organisasi merupakan jalan dalam meningkatkan poduktivitas organisasi itu sendiri.

\section{PENGERTIAN SUMBER DAYA MANUSIA}

Sumber daya manusia adalah kemampuan terpadu dari daya pikir dan daya fisik yang dimiliki individu, perilaku dan sifatnya ditentukan oleh keturunan dan lingkungannya, sedangkan prestasi kerjanya dimotivasi oleh keinginan untuk memenuhi kepuasannya.Sumber daya manusia merupakan aset dalam segala aspek pengelolaan terutama yang menyangkut eksistensi organiasi.Sumber daya manusia atau biasa disingkat menjadi SDM merupakan potensi yang terkandung dalam diri manusia untuk mewujudkan perannya sebagai makhluk sosial yang adaptif dan transformatif yang mampu mengelola dirinya sendiri serta seluruh potensi yang terkandung di alam menuju tercapainya kesejahteraan kehidupan dalam tatanan yang seimbang dan berkelanjutan.Dalam pengertian praktis sehari-hari, SDM lebih dimengerti sebagai bagian integral dari sistem yang membentuk suatu organisasi.Oleh karena itu, dalam bidang kajian psikologi, para praktisi SDM harus mengambil penjurusan industri dan Pengembangan Sumber Daya ..... 
organisasi. Mengenai perkembangan Sumber Daya Manusia dalam suatu organisasi, Greer menyatakan bahwa : Dewasa ini, perkembangan terbaru memandang SDM bukan sebagai sumber daya belaka, melainkan lebih berupa modal atau aset bagi institusi atau organisasi. Karena itu kemudian muncullah istilah baru di luar H.R. (Human Resources), yaitu H.C. atau Human Capital. Di sini SDM dilihat bukan sekedar sebagai aset utama, tetapi aset yang bernilai dan dapat dilipatgandakan, dikembangkan (bandingkan dengan portfolio investasi) dan juga bukan sebaliknya sebagai liability (beban,cost). Di sini perspektif SDM sebagai investasi bagi institusi atau organisasi lebih mengemuka.penggerak dari sumber daya lainnya yang dimiliki oleh organisasi dalam bentuk apapun.

\section{KOMPETENSI}

Kompeten adalah keterampilan yang diperlukan seseorang yang ditunjukkan oleh kemampuannya untuk dengan konsisten memberikan tingkat kinerja yang memadai atau tinggi dalam suatu fungsi pekerjaan spesifik. Kompeten harus dibedakan dengan kompetensi, walaupun dalam pemakaian umum istilah ini digunakan dapat dipertukarkan. Upaya awal untuk menentukan kualitas dari manajer yang efektif didasarkan pada sejumlah sifat-sifat kepribadian dan keterampilan manajer yang ideal. Ini adalah suatu pendekatan model input, yang fokus pada keterampilan yang dibutuhkan untuk mengerjakan suatu pekerjaan. Keterampilanketerampilan ini adalah kompetensi dan mencerminkan kemampuan potensial untuk melakukan sesuatu. Dengan munculnya manajemen ilmiah, perhatian orang-orang berbalik lebih pada perilaku para manajer efektif dan pada hasil manajemen yang sukses. Pendekatan ini adalah suatu model output, dengan mana efektivitas manajer ditentukan, yang menunjukkan bahwa seseorang telah mempelajari bagaimana melakukan sesuatu dengan baik. Terdapat perbedaan konsep tentang kompetensi menurut konsep Inggris dan konsep Amerika Serikat. Menurut konsep Inggris, kompetensi dipakai di tempat kerja dalam berbagai cara. Pelatihan sering berbasiskan kompetensi. Sistem National Council Vocational Qualification (NCVQ) didasarkan pada standar kompetensi. Kompetensi juga digunakan dalam manajemen imbalan, sebagai contoh, dalam pembayaran berdasarkan kompetensi. Penilaian kompetensi adalah suatu proses yang perlu untuk menyokong inisiatifinisiatif ini dengan menentukan kompetensikomptensi apa yang karyawan harus perlihatkan.

Pendapat yang hampir sama dengan konsep Inggris dikemukakan oleh Kravetz (2004), bahwa kompetensi adalah sesuatu yang seseorang tunjukkan dalam kerja setiap hari. Fokusnya adalah pada perilaku di tempat kerja, bukan sifat-sifat kepribadian atau keterampilan dasar yang ada di luar tempat kerja ataupun di dalam tempat kerja. Kompetensi mencakup melakukan sesuatu, tidak hanya pengetahuan yang pasif. Seorang karyawan mungkin pandai, tetapi jika 

kepandaian tidak berguna. Jadi kompetensi tidak hanya mengetahui apa yang harus dilakukan. Menurut Spencer and Spencer (1993) Kompetensi didefinisikan sebagai Underlying characteristic's of an individual which is causally related to criterionreferenced effective and or superior performance in a job or situation. Kompetensi merupakan karakteristik yang mendasari seseorang dan berkaitan dengan efektivitas kinerja individu dalam pekerjaannya. Secara general, kompetensi sendiri dapat dipahami sebagai sebuah kombinasi antara ketrampilan(skill), atribut personal, dan pengetahuan (knowledge) yang tercermin melalui perilaku kinerja (job behavior) yang dapat diamati, diukur dan dievaluasi. Dalam sejumlah literatur, kompetensi sering dibedakan menjadi dua tipe, yakni soft competency atau jenis kompetensi yang berkaitan erat dengan kemampuan untuk mengelola proses pekerjaan, hubungan antar manusia serta membangun interaksi dengan orang lain. Contoh soft competency adalah: leadership, communication, interpersonal relation, dll. Tipe kompetensi yang kedua sering disebut hard competency atau jenis kompetensi yang berkaitan dengan kemampuan fungsional atau teknis suatu pekerjaan. Dengan kata lain, kompetensi ini berkaitan dengan seluk beluk teknis yang berkaitan dengan pekerjaan yang ditekuni. Contoh hard competency adalah : electrical engineering, marketing research, financial analysis, manpower planning, dll.

\section{PROGRAM PELATIHAN DAN PENGEMBANGAN PEGAWAI}

Pelatihan dan pengembangan dapat didefinisikan sebagai usaha yang terencana dari organisasi untuk meningkatkan pengetahuan, keterampilan dan kemampuan pegawai. Pelatihan dan pengembangan merupakan dua konsep yang sama, yaitu untuk meningkatkan pengetahuan, keterampilan dan kemampuan. Tetapi apabila dilihat dari sasarannya, pelatihan lebih ditekankan pada peningkatan kemampuan untuk melakukan pekerjaan yang spesifik pada saat ini, dan pengembangan lebih ditekankan pada peningkatan pengetahuan untuk melakukan pekerjaan pada masa yang akan datang, yang dilakukan melalui pendekatan yang terintegrasi dengan kegiatan lain untuk mengubah perilaku kerja. Terdapat beberapa keuntungan dengan dilakukannya pelatihan dan pengembangan bagi pegawai yang pada akhirnya akan membawa keuntungan bagi organisasi diantaranya :

1. Mendorong pencapaian pengembangan diri pegawai

2. Memberikan kesempatan bagi pegawai untuk berkembang dan memiliki pandangan tentang masa depan kariernya.

3. Membantu pegawai dalam menangani konflik dan ketegangan.

4. Meningkatkan kepuasan kerja dan prestasi kerja. 
5. Menjadi jalan untuk perbaikan keterampilan dalam bersosialisasi dan berkomunikasi.

6. Membantu menghilangkan ketakutan dalam mencoba hal-hal baru dalam pekerjaan

7. Menggerakkan pegawai untuk mencapai tujuan-tujuan organisasi Berdasarkan halhal di atas maka pelatihan dan pengembangan sumber daya manusia memberikan dampak yang baik terhadap kinerja pegawai tersebut sebagai individu.

Hal ini jelas akan membawa peningkatan terhadap kinerja organisasi apabila pelatihan dan pengembangan pegawai dilakukan secara terencana dan berkesinambungan. Pengembangan SDM dirasakan sangat penting karena tuntutan pekerjaan yang sangat kompleks akibat kemajuan teknologi dan kompetisi diantara berbagai organisasi, sangat membutuhkan pengembangan pegawai yang baik. Beberapa tujuan dari pengembangan pegawai diantaranya :

1. Meningkatkan produktivitas kerja.

2. Meningkatkan efisiensi tenaga, waktu, bahan baku, dan mengurangi ausnya mesinmesin

3. Mengurangi tingkat kecelakaan pegawai.

4. Meningkatkan pelayanan yang lebih baik dari karyawan untuk konsumen perusahaan dan atau organisasi.

5. Menjaga moral pegawai yang baik.

6. Meningkatkan karier pegawai

7. Meningkatkan kecakapan manajerial pegawai

PENGEMBANGAN SDM BERBASIS KOMPETENSI DALAM MENINGKATKAN KINERJA ORGANISASI

Dalam mengungkap kinerja organisasi Nickson (2007:169) mengutip pendapat Armstrong mengenai yaitu : "Performance management is about getting better results from the organization, teams and individuals by understanding and managing performance within an agreed framework of planned goals, standards and competing requirements. It is a process for establishing shared understanding about what is to be achieved, and an approach to managing and developing people in a way which increases the probability that it will be achieved in the short and long term. It is owned and driven by management. "Berdasarkan pendapatnya di atas dapat dikatakan bahwa kinerja organisasi diperoleh dari pengelolaan berbagai tujuan, sasaran dan pengembangan sumber daya manusia di dalamnya dalam rangka mencapai tujuan baik jangka pendek maupun jangka panjang. Peran pimpinan dalam hal ini sangat dominan. Sejauh mana pimpinan menghendaki SDM organisasinya berkembang maka pimpinan tersebut 
memiliki kewenangan dalam mewujudkan pengembangan SDM melalui berbagai kegiatan pengembangan dan pelatihan sesuai dengan masing-masing kompetensi yang dimiliki pegawainya. Berbagai upaya pengembangan SDM hendaknya didukung oleh beberapa faktor diantaranya:

1. Terdapat seleksi SDM yang baik untuk benar- benar menciptakan pegawai yang berkualitas

2. Merancang keselarasan antara kebutuhan organisasi dan kemampuan pegawai

3. Menyediakan sarana, prasarana dan teknologi yang sesuai untuk pengembangan pegawai.

4. Komitmen tinggi dari setiap elemen organisasi untuk melakukan pengembangan pegawai secara berkesinambungan.

Apabila daya dukung organisasi sudah dapat berjalan secara simultan maka pengembangan sumberdaya manusia berbasis kompetensi akan dapat memberikan dampak baik bagi peningkatan kinerja organisasi. Hal ini terjadi karena sumberdaya manusia yang berkembang secara kompeten merupakan suatu kondisi dimana seluruh elemen internal organisasi siap untuk bekerja dengan mengandalkan kualitas diri dan kemampuan yang baik. Pada level tertentu dimana kondisi di atas sudah mampu tercipta dalam suatu organisasi maka kinerja individu organisasi menjadi cerminan bagi kinerja organisasi. Terdapat banyak tantangan dalam menciptakan situasi kondusif bagi organisasi untuk meningkatkan kinerjanya dan pengembangan SDM merupakan salah satu hal yang patut kian dilakukan. Organisasi yang menghendaki kinerja yang optimal dibutuhkan pula konsistensi dari manajemen mengenai pengelolaan pegawai yang baik dan proporsional serta menciptakan hubungan kerja yang efektif.

\section{METODE PENELITIAN}

Hal-hal penting dalam organisasi untuk memulai program kerja berdasarkan kompetensi :

\section{FOKUS BARU UNTUK DECADE BARU.}

Sebelum decade ini mencari penciptaan nilai dengan melihat keperusahaan kita. Pada tahun 1990 an pemenangnya adalah perusahaan yang mampu menguak nilai yang telah ada di perusahaan mereka, yakni para SDM yang andal, juga praktek dan system mereka.

b.Cara untuk meraih nilai. -Kemunculan teknologi informasi telah mengubah struktur kerja di banyak industry. -Membentuk tingkat keterampilan yang sesuai dengan perubahan peranan sampai pada pemahaman bagaimana struktur kerja dapat memenuhi kebutuhan motivasi 
pekerja. -Penekanan pada pengurangan jalur atau prosedur birokrasi sehingga birokrasi pada organisasi atau perusahaan dewasa ini, sekaranglebih flat (fleksible).

\section{METODE PRAKTIS.}

Adalah para professional dan para manajer menggunakan SDM yang terbaik di Organisasi mereka. Intinya kompetensi SDM berfungsi sebagai suatu yang berharga untuk diketengahkan yang memasukan semua kontribusi yang ada.

\section{PENERAPAN APLIKASI KOMPETENSI PADA SDM}

Perubahan system meliputi :system seleksi, system penilaian, evaluasi, perencanaan suksesi, perencanaan karier, dapat menggunakan secara fundamental dengan Bahasa yang sama. Banyak perusahaan sekarang mengambil jalan degan merubah secara drastic budaya mereka dan organisasi masa depan tidak banyak tergantung pada pimpinan visioner dari atas kebawah (top down), namun lebih banyak pada penekanan perilaku dan merubah respon individu terhadap situasi. Metode penelitian yang dipakai dalam kegiatan ini menggunakan metode praktis yaitu : hasil pengembangan Sumberdaya manusia yang telah dilakukan dievaluasi dengan menggunakan pemantauan secara langsung terhadap kinerja produksi. Dengan menggunakan grafik statistik dalam suatu periode tertentu dan dilihat naik turunnya kinerja realisasi produksi. Dengan demikian terlihat keberhasilan kinerja produksi pelumas.

\section{HASIL \& PEMBAHASAN}

\section{TAHAPAN-TAHAPAN YANG DILAKUKAN OLEH PT.PERTAMINA LUBRICANT MENUJU SDM BERBASIS KOMPETENSI.}

a.Training, Workshop dan Sertifikasi Kompetensi Personil. Sebagai perusahaan yang terus melangkah maju kedepan maka PT.Pertamina Lubricant, harus menetukan sikapnya agar bisnis pelumas yang menjadi tugas tanggung jawabnya terus berkembang. Dalam rangka menetapkan Pengembanagan Sumberdaya Manusia berbasis kompetensi maka memanfaatkan Lembaga Pendidikan di fungsi Sales \& Marketing yang disebut ILMA (Integrated Lubricant Marketing Academic) yang bertugas memberikan training tentang Pelumas dan Pelumasan kepada konsumen pemakai Pelumas Pertamina sekarang mendapat tambahan tugas memberikan training untuk meningkatkan kompetensi para karyawan PT.Pertamina Lubricant. Dengan demikian manajemen menetapkan bahwa ILMA adalah Integrated Lubricant Managemnt Academic dengan tugasnya sebagai Lembaga Pendidikan PT.Pertamina Lubricant yang melayani training konsumen (eksternal) dan melayani training karyawan (internal) atas permintaan HRD (Human Resorce Development) dan fungsi-fungsi lain di PT.Pertamina 
Lubricant. Beberapa training \& workshop yang telah dilaksanakan meliputi : -Basic Training Pertamina Lubricant for Production batch 1s/d batch 4 pada tahun 2017 dan batch 1 pada Januari 2018.

-Workshop Packaging \& Quality Control batch 1 s/d batch 4 pada tahun 2017 -Training Upskilling Arus Minyak PT.Pertamina Lubricant pada Pebruari 2018.

1. Training Pekerja Baru PT.Pertamina Lubricant pada Januari 2018

2. Training Salesmen Distribution Industri batch 1 pada Maret 2018

3. Sertifikasi Kompetensi Operator Blending Pelumas Pertamina di Production Unit Gresik pada tahun 2017 oleh Lembaga Sertifikasi Profesi (LSP) Migas. pada Januari 2018. -Sertifikasi Machine Lubrication Technology I dan II pada tahun 2017.

4. Sertifikasi Machine Lubrication Analysis I dan II pada tahun 2017.

5. Sertifikasi Salesman and Marketing pada tahun 2017. b. Evaluasi Training, Workshop dan Sertifikasi Kompetensi Personil.

-Evaluasi Training dan Workshop bagi para peserta didasarkan pada hasil penilaian Pretest dan Post-test. Dan bagi penyelenggara training termasuk Instruktur didasarkan pada Quitioner (daftar pertanyaan) atas kepuasan para peserta menerima pelajaran dari para instruktur. Dari hasil evaluasi tercatat ada kenaikan nilai dari Pre-test ke Post-test. Dari hasil evaluasi rata-rata para peserta menyatakan kepuasannya,danmendapatkan pengetahuan baru, menginginkan training dilakukan secara berkelanjutan dan diharapkan selalu ada peningkatan dari waktu ke waktu. Dibawah ini tabel 10 variabel Penilaian yang dipakai dalam Training / Workshop, 


\section{BERDASARKAN VARIABEL PENILAIAN SBB}

\section{Keterangan :}

SMH : Sangat Memenuhi Harapan

MH : Memenuhi Harapan

\begin{tabular}{|c|c|c|c|c|c|}
\hline .NO & $\begin{array}{l}\text { HAL YG DI } \\
\text { NILAI }\end{array}$ & .SMH &. $\mathrm{MH}$ &. $\mathrm{KMH}$ & .TMH \\
\hline 1 & $\begin{array}{l}\text { Materi pelatihan } \\
\text { yang diberikan }\end{array}$ & .4 & 6 & - & - \\
\hline 2 & $\begin{array}{l}\text { Sistemetika } \\
\text { penyajian }\end{array}$ & 1 & 8 & 1 & - \\
\hline 3 & $\begin{array}{l}\text { Metode / cara } \\
\text { penyajian }\end{array}$ & 1 & 8 & 1 & - \\
\hline 4 & $\begin{array}{l}\text { Pengaturan } \\
\text { waktu penyajian }\end{array}$ & 2 & 7 & - & - \\
\hline 5 & $\begin{array}{l}\text { Respon } \\
\text { instruktur } \\
\text { terhadap peserta }\end{array}$ & 2 & 7 & - & - \\
\hline 6 & $\begin{array}{l}\text { Relevansi } \\
\text { contoh dengan } \\
\text { materi }\end{array}$ & 2 & 7 & 1 & - \\
\hline 7 & $\begin{array}{l}\text { Penguasaan } \\
\text { Instruktur }\end{array}$ & 3 & 7 & 1 & - \\
\hline 8 & Diskusi & 1 & 8 & 1 & - \\
\hline 9 & $\begin{array}{ll}\begin{array}{l}\text { Sarana } \\
\text { prasarana }\end{array} & \text { dan } \\
\end{array}$ & 3 & 7 & - & - \\
\hline 10 & $\begin{array}{l}\text { Konsumsi dan } \\
\text { pelayanannya }\end{array}$ & 3 & 7 & - & - \\
\hline & Total & 22 & 72 & 5 & - \\
\hline
\end{tabular}

KMH : Kurang Memenuhi Harapan

TMH : Tidak Memenuhi Harapan

\section{BERDASARKAN KESESUAIAN KEBUTUHAN MATERI DENGAN PROFESI \\ DITEMPAT KERJA}

\begin{tabular}{|r|l|c|c|c|}
\hline No & URAIAN & SESUAI & TIDAK & SESUAI \\
\hline 1 & $\begin{array}{l}\text { KET } \\
\text { Relevansi } \\
\text { kengan } \\
\text { kebutuhan } \\
\text { profesi di } \\
\text { tempat kerja }\end{array}$ & 15 & 0 & - \\
\hline
\end{tabular}

Evaluasi dari Sertifikasi Kompetensi Personil bagi para peserta didasarkan tingkat kelulusan dari hasil ujian kompetensi oleh Lembaga yang berkompeten. Dan sertifikasi berlaku selama 5 tahun, dan setiap tahun diadakan assesmen oleh Lembaga yang berkompeten. Pada umumnya para peserta yang menyandang sertifikasi kompetensi menyatakan bangga karena ada pengakuan secara resmi atas kompetensi mereka. Dan para peserta dilapangan dirasakan lebih bertanggung jawab dalam pekerjaannya hal ini disampaikan oleh atasan langsung. 
Kedepan manajemen PT.Pertamina Lubricant akan terus meningkatkan dan memperbaiki sistem pendidikan dan pelatihan ini yang ternyata manfaatnya banyak dirasakan baik oleh masing-masing karyawan maupun oleh Organisasi PT.Pertamina Lubricant.

Pengaruh Pengembangan Sumberdaya Manusia terhadap kinerja produksi pelumas setelah dilakukan Sertifikasi Kompetensi Profesi, Training dan Workshop tidak serta merta terjadi perubahan. Namun jika dilihat dari perkembangan realisasi produksi tahun 2018 meningkat terus untuk mencapai program produksi. Hal ini menunjukan bahwa peningkatan kompetensi profesi berdampak cukup baik terhadap kinerja produksi. Dibawah ini grafik realisasi produksi pelumas 2018 di Production Unit Gresik yang telah menggunakan program Training, Whorshop, dan Sertifikasi Kompetensi Profesi.

REALISASI PRODUKSI PELUMAS 2018

\begin{tabular}{|c|c|c|}
\hline BULAN & $\begin{array}{c}\text { PROGRAM } \\
(\text { KL })\end{array}$ & $\begin{array}{c}\text { PRODUKSI } \\
(\text { KL })\end{array}$ \\
\hline JANUARI & 13,733 & 8,400 \\
\hline FEBRUARI & 15,525 & 10,301 \\
\hline MARET & 12,469 & 11,492 \\
\hline APRIL & 12,558 & 12,040 \\
\hline MEI & 14,074 & 12,962 \\
\hline
\end{tabular}

\section{Sumber : Production Unit Gresik}

Lebih jelasnya dapat dilihat dari Grafik perkembangan realisasi produksi Pelumas di Production Unit Gresik dibawah ini.:

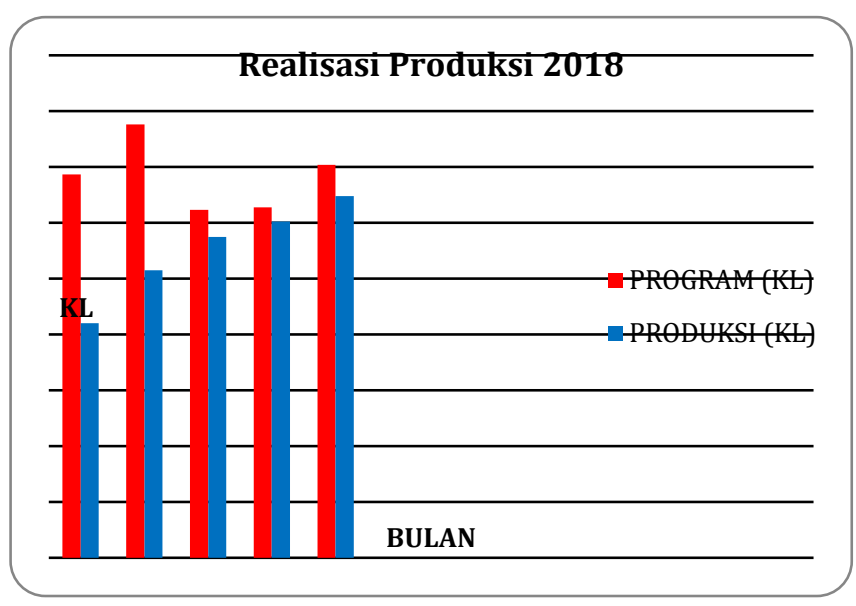




\section{SIMPULAN \& SARAN}

Berdasarkan pembahasan hasil penelitanpada bab sebelumnya, hasil pengolahan data dan uji hipotesis yang telah dilakukan maka penulis mengambil kesimpulan sebagai berikut :

\section{Simpulan}

Pengembangan SDM yang berbasis kompetensi dapat membantu organisasi untuk memiliki sumber daya manusia yang kompeten dan handal dalam bekerja. Melalui berbagai kegiatan pengembangan dan pelatihan, kompetensi SDM akan lebih optimal dan berujung pada meningkatnya kinerja organisasi melalui penjabaran serta operasionalisasi visi dan misinya.

\section{Saran}

Pengaruh Pengembangan Sumberdaya Manusia terhadap kinerja produksi pelumas setelah dilakukan Sertifikasi Kompetensi Profesi, Training dan Workshop tidak serta merta terjadi perubahan. Namun jika dilihat dari perkembangan realisasi produksi tahun 2018 meningkat terus untuk mencapai program produksi. Hal ini menunjukan bahwa peningkatan kompetensi profesi berdampak cukup baik terhadap kinerja produksi. Dibawah ini grafik realisasi produksi pelumas 2018 di Production Unit Gresik yang telah menggunakan program Training, Whorshop, dan Sertifikasi Kompetensi Profesi.

\section{DAFTAR PUSTAKA}

Alwi, Syafaruddin. 2001. Human Resource Management: Competitive Superior Strategy. BPFE.Yogyakarta.

Hasibuan, Malayu. 2001. Human Resource Management. Earth Script. Jakarta.

Nickson, Dennis. 2007. Human Resources Management for The Hospitality and Tourism Industries. Elsevier, Burlington.

Puwatno.\&Priansa, D. 2011. Manajemen SDM dalam organisasi Publik dan Bisnis. Bandung: Alfabeta. Martin dan Luthans 2010, Organizational Behavior (New York : McGraw-Hil Book Company

Rivai, Veithzal. 2011. Manajemen Sumber Daya Manusia Untuk Perusahaan. Jakarta: PT Raja Grafindo Persada.

Rivai, Veithzal. \&Sagala, E.J. (22010 Manajemen Sumber Daya Manusia untuk.Perusahaan. Jakarta: Raja grafindo Persada.

Rhineshmith, Gilbert.2011, Introduction to Mass Communication, Edisike Sembilan, Harrpper Rof publisher, New York. 
Robbins, S.(2012). Management, 10th edition. New Jersey : Pearson Prentice Hall

Robbin P. Stephen.2012. Perilaku Organisasi, Konsep, Kontroversi dan Aplikasi. Edisi Kedelapan. Jakarta : Prenhallindo.

Ryllatt, Alastair, et.al, 1995. Creating Training Miracles.AIM. Australia.

S Greer, Charles R. 1995. Strategy and Human Resources: a General Managerial Perspective. New Jersey: Prentice Hall.

Spencer, N.Lyle and Spencer, M. Signe. 1993. Competence at Work: Models for Superrior Performance. John Wily \& Son, Inc. New York USA

Spencer,M.Lyle and Spencer, M. Signe, 2011 Competence at Work:Models for Superrior Performance, John Wily \&Son,Inc,NewYork,USA

Stoner, James A. F. \& Edward Freeman, Daniel R. Gilbert, Jr. (2004). Manajemen. Edisi Indonesia, Alih Bahasa Alexander Sindoro, PT. Prehallindo, Jakarta.

Soegiono.2012, Metode Peneliian Bisnis., Gramedia Pustaka, Jakarta.

Soegiono.(2012). MetodePenelitianBisnis.Jakarta : GramediaPustakaUtama

Sangkala. 2010. Knowledge Management. Jakarta: PT. Rajagrafindo Persada http://johantambotoh.wordpress.com/ 2010/08/05/membangun-budaya- yang-berpusatpada-pengetahuan/. (5 Agustus 2010)

Umar, Husein. 2010. Desain Penelitian MSDM dan Perilaku Karyawan. Paradigma Positivistik dan Berbasis Pemecahan Masalah. Jakarta: PT Raja Grafindo Persada.

Umar, Husein.2012, Metode Penelitian Untuk Skripsi dan Tesis Bisnis, PT. Raja GrafindoPersada, Jakarta

Von Krough, Ichiyo, serta Nonaka (2000) dan Chun Wei Choo (2006)

Wibisono, Dermawan. 2011. Panduan Penyusunan Indikator. Manajemen Kinerja Korporasi \& Organisasi. Jakarta :GramediaPustakaUtama.

Wibowo, (2012), Manajemen Kinerja, Penerbit PT. Raja Grafindo, Jakarta. http://satria.anandita.net/kuliahmanajemen-pengetahuan-gratis. (31 Maret 2015) Yulk G. A. and Wexley K.N. 2011, Organization Behavior and Personnel Psychology. Richard D. Irwin, Homewood Illinois 